\title{
Peculiarities of News and Analytical English-Language Media Texts About Russia
}

\author{
Yulia Yuzhakova, Liliya Polyakova, Elena Suvorova, and Tatiana Emets \\ Nosov Magnitogorsk State Technical University, 38, Lenin Str., Magnitogorsk, Russia
}

\begin{abstract}
The article is devoted to the consideration of peculiarities of the English-language news and analytic media texts about Russia, which contribute to the formation of a certain attitude towards this country. It is noted that the scope of media texts in English prevails in the global information space, which cannot but affect the viewpoint of the "average" English speaking reader. The notion of ideological modality, which is often present in media texts about Russia, is considered. The media text compositional peculiarities and linguistic means are described in connection with the impact function implementation and the certain attitude towards Russia formation.
\end{abstract}

\section{Introduction}

Currently, media texts (or mass media texts) are the most common type of texts. Media text is a specific term to the generic notion of mass-information discourse. A separate media text is a single material implementation of mass information discourse. The mass information discourse can be characterized in the following way: an author of a media text distantly interacts with a mass heterogeneous audience for the purpose of informing, convincing, providing the audience with interpretation of current events, etc.

In scientific database, the following types of media texts are usually distinguished: news texts that implement an informative function; information-analytical texts representing an expanded version of the news text, containing not only news, but also commenting, analytical part; texts of the "features" group, emphasizing the factor of human interest, highlighting this or that problem from the entertaining side, emphasizing the individual author's vision.

We are interested in news and analytical Englishlanguage media texts representing political discourse. Such texts represent an ideological modality, based on the opposition "us - them", which can be not explicated, but included in the presupposition of the media text. For psychological reasons, "them" (the "other", "alien") is initially perceived negatively by the reader. So the author of a political text affects the reader's viewpoint intentionally or not.

\section{Literature Review}

E. Klyuev [1] identifies three types of verbal intentions: neutral, positive and negative.

1. Positive speech intention implies expurgating the referent. The communicative strategies, corresponding to this type of intention, are aimed at forming positive assessments of the referent. 2. Negative intention implies demonizing the referent. The communicative strategies, corresponding to this type of intention, are aimed at forming negative assessments of the referent. 3. Neutral (constructive) intention presupposes painting the referent in true colors. Constructive intention means an invitation to analyze the referent.

In news texts, a neutral intention should be implemented, but the author does not always manage to keep a neutral tone, because he cannot completely abstract his mind from his community values and involuntarily expresses his community attitude to "them" (the "other", "alien"), thus influencing the reader's point of view. In analytical texts, the author can be guided by neutral, negative or positive intentions, forming the required attitude to the referent.

The purpose of our research is the identification of news and analytical English-language media text peculiarities, in other words we are supposed to consider compositional features and linguistic means that allow the author to influence the addressee's opinion. The main method of our study is the method of pragmatic analysis which involves learning communication participants' goals, their intentions and communicative actions and operates with notions such as speech strategy and tactics. 
Speech tactics mean one or several actions that contribute to the implementation of the strategy [2]. The aim of the specific tactic application is to change the reader's worldview in a certain way: to strengthen certain desires, to change the attitude toward certain phenomena and events, to transform the image of any situation [2].

According to O. Issers [2], speech tactics have the following characteristics:

1. Semantic: a) the reference peculiarities (the identification of communication participants; the designation of objects, events, actions; the evaluation of communicative situation characteristics; the determination of relations between participants, b) the knowledge of the world (frames and scenarios help to recognize speech tactics); c) the implicit components of the utterance (presuppositions, settings, etc.), etc.

2. Lexical: a) stylistic criteria of words; b) the expressivity category; c) markers on the speech "surface": particles, connectives, repetitions, discourse words, etc.

3. Lexical-grammatical and syntactic: a) affective and emotional syntax; b) syntactic structures' transposition, etc.

4. Pragmatic: a) the sequence of communicative moves; b) the whole complex of communicative moves, etc.

Recognition of the communicative task occurs on the basis of all the levels - surface and cognitive structures, pragmatic features should also be taken into account. In other words, while interpreting strategies and tactics, we should pay attention to the indicators of all kinds [2].

Taking into account the aforesaid, it is necessary to note the need to expand the methodological base and add to the pragmatic analysis method the following methods: the discourse analysis method, the contextual analysis method, the cultural interpretation method, the component semantic analysis method, the stylistic analysis method. In other words, the methodological basis of our study is the complex of linguistic analytical methods.

In Russia, the most common definition of the text is the definition proposed in "The Big Encyclopaedic Dictionary. Linguistics": "Text is a sequence of sign units united by a sense connection, the main properties of which are coherence and integrity" [3]. As a result of the development of mass media, the concept of "text" expanded its scope, received new elements of meaning. This process is primarily related to the overlapping of the verbal (speech) component of the text with its media component, which ensures the communication of this text with the help of certain media. As a result, the notion of "media text" appeared, which contains both verbal and media characteristics in its structure. This term began to be used at the end of the 20th century in the Englishlanguage scientific literature, in the works of A. Bell [4 6], T. Van Dijk [7, 8], M. Montgomery [9, 10], N. Fairclough [11-15], R. Fowler [16], who conducted their research in the field of sociolinguistics, discourse theory, cognitive linguistics, content analysis. The study of media texts in terms of functional stylistics, text stylistics, discourse analysis and rhetoric was also conducted by Russian scientists, I. Galperin [17], T.
Dobrosklonskaya [18, 19], V. Odintsov [20], G. Solganik [21] and others.

A. Bell in the book "Approaches to Media Discourse" [4] describes the media text as follows: "The definition of media text goes beyond the traditional view of the text as a sequence of words printed or written on paper. The concept of media text is much broader: it includes voice qualities, music and sound effects, visual images - in other words, media texts actually reflect the technologies used for their production and distribution" This definition focuses on the interaction and interpenetration of verbal and media characteristics of media text, which is its distinctive feature.

However, we should note that we are not supposed to study the peculiarities of audio-visual impact of media texts; therefore we are going to consider newspaper and magazine texts only as the examples of written speech.

It should be remembered that the information content of the media text has some peculiarities: the text not only contains facts, but also offers comments and reflections of the author, who does not aim at the thorough description of the object, but only covers the aspects that interest the potential reader. The main purpose of the mass media text is to influence the consciousness of the mass addressee, to form the reader's position in relation to the facts described.

When we talk about the realization of the impact function, we cannot but refer to the works in the field of pragmalinguistics by G. Grice [22], G. Leech [23] R. Lakoff [24], P. Brown and S. Levinson [25]. This research is continued by contemporary linguists nowadays [26 - 30].

Mass information texts do not vary greatly in compositional (structural) patterns. Most often they are composed according to a certain scheme. It is customary to distinguish four parts in media texts: the heading, the introductory part, the main part and the conclusion. The introductory part represents the theme, helps the author to get the reader's attention, to establish contact with him. The main part develops the theme; the message of the subject is stated. Conclusion sums the information up, offers insight. According to T. Dobrosklonskaya [6], in English-language journalism, such structure of news media texts is called the inverted pyramid principle, which assumes that "all the most valuable and important information is reported at the beginning of the text, with the main information load being the first phrase that actually contains all the most important components of the message in a concentrated form. As the text is being developed, the information load is gradually weakening". In other words, the "framework" of media text (the headline, the introductory part and the conclusion) manifests its ideological orientation and largely influences the reader's perception of the entire text. The tone of the "framework" affects the reader's perception of the proposed information: in a positive, negative or neutral way. 


\section{Analyses}

The headline is the main attractor of the reader's attention. Its principal task is to "hook" the reader, to intrigue him, to force him to begin reading the proposed text. Due to the performed function, many headings are emotionally and expressively colored, they are characterized by a deviation from the neutral style of presentation, from the norm of the language that makes the reader pay attention to the proposed text. The headings of texts describing identical events can differ significantly in their tonality, i. e. by the degree of expression of the author's attitude to the presented facts, in other words, by the degree of the impact function realization.

Most of the newspaper texts, considered by us, either contain a negative evaluation of Russia and events taking place in it, or are neutral, i.e. perform only an informative function. The headings adequately reflect this trend. The neutral headings, in our opinion, are:

Deportation of Uzbek by Russia is Criticized (The Washington Post; 27.10.06). Dispute between Georgia, Russia Escalates (The Washington Post; 30.09.06). Russia near Deal to Join the W.T.O. (The New York Times; 11.11.06). Ex-spy Buried in London: Russia Opens Criminal Case (The USA TODAY; 7.12.06). Abramovich Seeks to Quit as Russian Regional Governor (The FT; 21.12.06). Putin Denies Role in Death of Ex-spy (The FT; 24.11.06). Gas Giant Buys Russia's Leading Paper (The Guardian; 22.11.06). Georgia Releases Russian Officers (The Guardian; 02.10.06). Putin Blames Georgia for Caucasus Unrest (The Guardian; 21.10.06). Ukraine Debates Disputed Election (The Daily Mail; 27.11.06).

The following headings contain a negative evaluation, veiled and toned down in various ways. A nuanced analysis of the ways to implement negative evaluation can be found in [31].

Russia, a Glass Half Full? (The CSM; 04.03.05)

This title contains an allusion to a well-known saying about how pessimists and optimists view things. The author seems to hold a pessimistic view of Russia, but expresses this position not by approving it (using a pessimistic view in an affirmative form), but questions the optimistic view using an elliptical general question. Thus, the author does not state the negative, but questions the positive, which makes the overall tonality of the title softer.

Russia's Half-Truth (The CSM; 10.05.05)

The noun half-truth contains the seme of the incomplete adequacy of the proposed information to the reality, in other words, lie. But the lie refers only to the content plane, it is implied. In the expression plane, in the form of the word (half-truth), truth, although incomplete, is explicated. Using such dictionary helps the author reduce the title directness, toning the negative evaluation down.

Russian Ex-Spy, a Putin Critic, Dies in London after Poisoning (The Washington Post: 24.11.06)

This title is completely neutral in terms of expression: it does not contain expressive emotionally colored lexical items. According to the form (structure) it is an affirmative sentence, a simple statement of the fact. At the same time, the heading in question contains the apposition a Putin critic and, thus, implicates some involvement of Mr. Putin in this event (Poisoning). This implication, in accordance with Grice Cooperation Principle (Grice, 1985), is based on the amount of information maxim ("do not share information that is superfluous", i.e. any information mentioned is considered important). So having learnt that the ex-spy was a Putin critic, a reader, wishing or not, links the spy's death to this fact. The ascertaining a fact modality of this heading contributes to this greatly.

There are also more expressive, emotionally colored headlines, which have pronounced evaluability: The Darkness Spreading Over Russia (The Washington Post; 21.10.06); The Russian Bear Is Back-and this Time It's Gas-powered (The Guardian; 13.05.06); Behind the Assassins, the Grim Truth of Putin's Russia (The Observer; 26.11.06); Corruption, Violence and Vice Have Triumphed in Putin's Russia (The Guardian; 27.11.06); Obnoxious, but Gas War Is not Putin's Worst Crime (The Times 04.01.06).

All these headings are characterized by the presence of nouns and phrases that have obvious negative connotations: the Darkness; Gas-powered; the Grim Truth; Corruption, Violence and Vice; The Worst Crime. Moreover, all these headings have the form of affirmative sentences having the ascertaining the fact modality, which facilitates their perception by the reader as the truth. Thus, the combination of negative dictionary connotation and the ascertaining the fact modality in one sentence effectively performs the impact function and creates a negative image of Russia in readers' minds.

The media text introductory part following the headline explains it, expands on it, comes down to the theme and catches the reader's interest. The headline, the introductory part and the conclusion form a kind of framework, a package in which the main information of the media text is placed. Psychologists say that the first and the last utterances in speech make the greater impression on the addressee and they are remembered better. The "packaging" of a newspaper text, consisting of a headline, an introductory part and a conclusion, can be compared to the initial and final utterances that significantly affect the perception of the whole text. The tone of the "framework" defines how the reader will perceive the proposed information: in a positive / negative way or neutrally.

The headline of the text, "Russia, a Glass Half Full?" (The CSM; 04.03.05), conveying the author's doubts about the evaluation accuracy of the situation in Russia, is followed by the introductory part:

For the last 10 days, Russia's backsliding on its young democracy has been under intense scrutiny. The retrogression dominated the press conference between Presidents Bush and Putin in Slovakia last week, with Mr. Bush chiding his soul-mate "Vladimir" about the necessity for free media, rule of law, and vibrant political opposition.

This beginning, like the headline, is supposed to reflect the author's desire to understand the current situation in Russia, in other words we can trace the 
author's neutral intention. Nevertheless, neutral intentions are not always fully realized in mass media texts, which typically have an ideological modality corresponding to one or another system of values and socio-political views. So, the phrase "Russia's backsliding on its young democracy", used at the very beginning of the text, is a nominal structure which has a stating the fact modality, which gives the impression that the above-mentioned situation in the country is real. The basis of the phrase under consideration is the contrast of the lexical item, which has a positive connotation in the western system of values (democracy) and the lexical item containing a negative connotation (backsliding). This phrase specifies the general negative tone of the introductory part, which is supported by the use of other lexical items with negative connotations (backsliding, retrogression; to chide). It should be noted that the verb to chide implies the superiority of the agent in relation to the patient, his having a right to do so. It explains the author's choice of this lexical item and reflects his ideological values. However, the author does not use this lexical item in the form of a predicate, which would make the statement ruder. The author uses a participial construction instead, expressing the attendant circumstances of the setback: with Mr. Bush chiding his soul-mate "Vladimir". It helps tone down the statement. The choice of the direct object (the phrase his soul-mate "Vladimir") to the participle chiding contributes to the same aim: it tones down the statement and neutralizes to some extent the seme of the patient subordination. An indirect prepositional object about the necessity for free media, rule of law, and vibrant political opposition also refers to the participle chiding. The noun necessity implies the absence of all the above-mentioned phenomena in Russia. These phenomena constitute the basis of the Western democracy, so the reportedly lack of these democratic features in Russia can create a negative image of Russia in western readers' minds.

In the concluding part of this text:

Still, as President Bush navigates relations with Moscow, and as members of Congress throw out suggestions like suspending Russia from the $G-8$, they would do well to consider the full contextual landscape of that vast and complex country, the author uses an adversative-concessive structure. The first part of which contains the description of real actions of the American president and representatives of the congress. The Actions of the president (navigates relations with Moscow) are evaluated neutrally, as the verb to navigate does not contain any connotations. The actions of the congress are evaluated negatively, since the phrase throw out suggestions has negative connotations.

The second part of the sentence represents an implicit advice to the President and The Congress, how to treat Russia. The veiled advice is expressed through a subjunctive mood: they would do well to consider the full contextual landscape of that vast and complex country. The phrase vast and complex country, containing epithets vast and complex indicates the author's respect for Russia. The phrase, consider the full contextual landscape, testifies to the author's desire to see into the matter, taking into account the cultural and historical peculiarities of the country. Thus, the conclusion of the text, the headline and the introductory part, implements the author's neutral (constructive) intention, his desire to objectively define the situation in Russia. Probably, the reader's viewpoint on Russia will also be constructive.

Another peculiarity of news and analytical media texts is a great number of quotations used in them. In the mainstream of this research, citation interests us precisely in terms of implementing the communicative intention of the author. It seems that the citation allows the author to carry his intention into effect (to express his attitude to the referent, to inspire this attitude to the reader), using the words of other people. With the help of this technique, the author disassociates himself from what has been said and pretends to be a person who only conveys information, a messenger of someone else's opinion. If one of the cited analysts permits a sharp statement, then he is to blame, the author himself remains an impartial and objective observer.

Quotations can be used as illustrations, on the basis of which the author makes different conclusions. Thus, the text, Double Talk on Democracy (The USA TODAY, 08.05.06), contains an analysis of Cheney's speeches delivered during his visit to the countries of Central Asia and Eastern Europe. This text is based on comparing and contrasting Cheney's statements about the situation in Russia and the Central Asian republics in terms of their democratic reforms. Parallel syntactic constructions serve as a basis for such an opposition: He scolded Moscow for using oil and natural gas as "tools for intimidation and blackmail." He admired "all that's been accomplished in the last 15 years, both in the economic and the political realm." The verb to scold, having negative connotations, along with the verb to admire, which has positive connotations, produce the effect of contrast. This contrast is enhanced by the use of citations of negative ("tools for intimidation and blackmail") and neutral ("all that's been accomplished in the last 15 years, both in the economic and the political realm") sentiment. The author uses the contrast technique to demonstrate the contradictions in Cheney's speech: the development of democracy in Russia, a relatively democratic country, Cheney evaluates negatively, at the same time his perception of the development of democracy in the Central Asian countries, and the countries with the authoritarian rule is rather positive. The contrast under consideration is summed up with the following words: The blatant display of different strokes for different folks is understandable - and unacceptable. Thus, the technique of contrast along with the using quotations allows the author to demonstrate contradictions in the position of the referent, make the reader think about current events, in such a way neutral intention is implemented.

The author's comments (remarks), indirectly characterizing the quoted speaker, affect greatly the reader's perception of quotations and, consequently, of the whole text. Formally, the author simply introduces a speaker, offers the reader actual information about his occupation and activities. But in accordance with G. Grice's Cooperation Principle (the amount of information maxim), the reader understands that such a lengthy comment represents a certain characteristic of the 
speaker. Such remarks can be used to form a certain attitude to the speaker and his words. In this case we deal with the opposition "us - them" again. The attitude of the reader depends, first of all, on the coincidence / inconsistency of his own value orientations and value orientations of the quoted speaker. The agreement of the worldview leads to the formation of a positive attitude to the speaker and his words; sharp differences that cause negative perception of the speaker and the skeptical attitude to his words. Thus, the author's remarks (comments), which are indirect characteristics of speakers, help the reader to orientate himself in the axiological space of the text and adhere to the viewpoint of those speakers whose value orientations agree with the reader's value orientations. Thus, the opinion of a positively perceived speaker ("us") is more likely to convince the reader of its correctness, to be accepted without question by the reader than the viewpoint of "them", "an alien" (a person with opposite views who is perceived negatively).

Thus, the author uses remarks to help the reader orientate in the axiological space of the text, and ultimately form the reader's position. However, alongside with the performing axiological functions, the author's remarks are intended to testify his impartiality and objectivity, his allegedly neutral intentions.

The author can demonstrate his impartiality and objectivity, using phrases like Experts say, which are often followed by a negative evaluation of the referent. Using this technique, the author, first, disassociates himself from the explicit negative modality of the "experts" and "reliable sources" quotation; pretends to be an objective observer, and, secondly, convinces the reader of the correctness and truthfulness of the words based on eyewitness accounts and expert opinion:

Witnesses said the bitterly divided Rada dissolved into "pandemonium" at the news, with fisticuffs, angry shouting matches, and at least one attempt to storm the podium (Ukraine's Pro-democracy Reforms in Doubt; The CSM; 12.07.06).

This sentence contains a rather vivid and emotional description of events in the Rada: the metaphor "pandemonium" is used, illustrated by the list of events occurring in the Rada: fisticuffs, angry shouting matches, and at least one attempt to storm the podium. However, this word-painting does not belong to the author; it belongs to the "witnesses", who should be responsible for the excessive emotionality of the utterance.

Human rights groups have charged that Putin inflamed passions here when he said that wholesale markets, where many members of ethnic minorities work, should be monitored "to protect the interests of Russian producers and population, the native Russian population." (Putin Says He'll Retain Influence in Russia after Term Ends in '08; The Washington Post; 26.10.06).

This sentence contains accusation of Putin of stirring ethnic hatred. However, the author conceals his own attitude toward this issue, giving the word to the Human rights groups. Nevertheless, the reader can perceive the author's silence as his consent to the accusation.

Critics say that the Party of the Regions is still a front for Russia-linked businessmen and criminals in eastern
Ukraine, pointing to $\mathrm{Mr}$ Yanukovych's criminal convictions as a young man. (Revolution is reversed with a little spin from the West; The Times; 28.03.06).

In this case, the author acts as a transmitter of the critics' opinion. He plays safe not to state himself the information that may be unreliable. Thus, if the information is false, critics are to blame.

So the use of citation in the media text differs from the use of citations in other types of texts. The main function of quotations in media texts is not an illustrative function, but an impact one making a reader adopt the author's viewpoint.

\section{Conclusion}

During the study of the English-language media texts about Russia, the following peculiarities of the media text composition were revealed [32], which make it possible to form the reader's attitude towards the referent:

a) media text "packaging" or "framework" (the headline, the introductory part, the conclusion) displays the author's value orientations and greatly affects the perception of the entire text by the reader. The tone of the "framework" defines how the reader will perceive the proposed information: positively, negatively or neutrally;

b) a great number of citations is intended to indicate, firstly, the author's supposed objectivity (the author gives the right to speak to all interested parties); secondly, the truthfulness of the information is implied (either "reliable sources" or known people serve as the source of information) and, thirdly, the use of many citations is supposed to demonstrate the author's impartiality, his equal attitude to the opinions of all the interested parties, that is his neutral intentions. All these help the author to transfer the necessary attitude to the referent;

c) author's comments or remarks, which are indirect characteristics of the speakers, represented by quotations, help the reader to orientate himself in the axiological space of the text and to adjoin the viewpoint of those speakers whose worldview agrees with the reader's.

d) citation allows the author to implement his intention (to express his attitude to the referent, to inspire this attitude to the reader), using the statements of other people. Using this technique, the author disassociates himself from what has been said and pretends to be a person who only conveys information, an impartial and objective transmitter of someone else's opinion, which also contributes to the introduction of a certain attitude towards the referent into the reader's consciousness.

\section{References}

1. E. Klyuev, Speech Communication (RIPOL CLASSIC, Moscow, 2002)

2. O. Issers, Communicative Strategies and Tactics of Russian Speech (Editorial URSS, Moscow, 2003)

3. V. Yartseva et al, Linguistics (The Big Russian Encyclopaedic Dictionary, Moscow, 2000)

4. A. Bell, Approaches to Media Discourse (Blackwell, Oxford, 1998) 
5. A. Bell, Time and Society 4, 305-328 (1995)

6. A.Bell, The Language of News Media (Blackwell, Oxford, 1991)

7. T. Van Dijk, Language. Cognition. Communication (Progress, Moscow, 1989)

8. T. Van Dijk, Ideology: A Multidisciplinary Approach (Sage Publication, London, 1998)

9. M. Montgomery, B. Edington, The Media (The British Council, London, 1996)

10. M. Montgomery, An Introduction to Language and Society (OUP, London, 1992)

11. N. Fairclough, Language and Power (Longman Group, UK, 1989)

12. N. Fairclough, Discourse and Social Change (Polity Press, Cambridge, 1992)

13. N. Fairclough, Media Discourse (Edward Arnold, London, 1995)

14. N. Fairclough, Analysing Discourse: Textual Analysis for Social Research (Routlege, London \& New York, 2003)

15. N. Fairclough, Language and Globalization (Routledge, London and New York, 2006)

16. R. Fowler, Language in the News: Discourse and Ideology in the Press (Routledge, London and New York, 1991)

17. I. Galperin, The Text as an Object of Linguistic Research (Nauka, Moscow, 1981)

18. T. Dobrosklonskaya, Questions of the Media Text Study (Experience in the Study of Contemporary English Media) (Editorial URSS, Moscow, 2005)

19. T. Dobrosklonskaya, Medialinguistics: A System Approach to the Study of the Media Language: A Modern English Media Report (Flint, Moscow, 2014)
20. V. Odintsov, Stylistics of the Text (KomKniga, Moscow, 2006)

21. G. Solganik, Stylistics of the Text (Flint: Nauka, Moscow, 2001)

22. G. Grice, News in Foreign Linguistics 16, 217-237 (1985)

23. G. Leech, Principles of Pragmatics (Longman, London and New York, 1983)

24. R. Lakoff, Papers from the 9-th Regional Meeting of the Chicago Linguistics Society, 292 - 305 (1973)

25. P. Brown, S. Levinson, Politeness: Some Universals in Language Usage (Cambridge Univ.Press, Cambridge, 1987)

26. A. M. Alo, A. Orimogunje, Southeast Asian Journal of English Language Studies 19(2), 111-123 (2013)

27. N. Ibrahim, F. Mohd, Journal of Language Studies 14(1) (2014)

28. S. Nawaz, A. H.Bilal, M. Kalsoom, Z. Fayyaz, H. Nayyar, Asian Journal of Social Science and Humanities 2(2), 328-337 (2013)

29. R. Ramanathan, \& T. Bee Hoon, Southeast Asian Journal of English Language Studies 21(2), 57-68 (2015)

30. M. Tahir, Middle-East Journal of Scientific Research 14(6), 744-753 (2013)

31. Yu. V. Yuzhakova, Proceedings of the 10-th International Conference "Issues of Modern Philology and Methods of Language Teaching at University and School", 109-111 (2007)

32. Yu. V. Yuzhakova, Proceedings of the International Conference "Language. Culture. Communication", $403-405$ (2008) 